\title{
Characteristics, training loads, injury patterns and stretching habits of Australian Ironman Triathletes
}

\author{
Warren H. Ansell \\ BAppSc(Phyt), PostGradDip(SportsPhysio)
}

A thesis submitted in fulfilment of the requirements for the degree of Master of Medical Science (Physiotherapy)

The University of Newcastle

New South Wales

Australia

February 2012 


\section{ACKNOWLEDGEMENTS}

I would like to acknowledge the assistance provided by the following people, who made the completion of this project possible.

Professor Darren Rivett, Head of School of Health Sciences, who as principal supervisor used his academic knowledge and publishing experience to provide invaluable input throughout my candidature.

Professor Robin Callister, Discipline of Human Physiology, who as co-supervisor provided valuable feedback, advice and support throughout this study.

Ken Baggs, race director of the Australian Ironman Triathlon. Without his support I would never have had access to the athletes or the registration packs for distribution.

Finally my long suffering wife, family and friends who smiled and nodded while I bored them to tears with the nuances of stretching and Triathlon. 
I hereby certify that the work embodied in this thesis is the result of original research and has not been submitted for a higher degree to any other University or Institution

Warren H. Ansell 


\section{TABLE OF CONTENTS}

ACKNOWLEDGEMENTS

TABLE OF CONTENTS

LIST OF TABLES

LIST OF FIGURES

IV

ABSTRACT

V

CHAPTER 1 INTRODUCTION

1.1 Background

1.2 Aims and hypotheses

1.2.1 Aims

1.2.2 Hypotheses

1.2.3 Null hypotheses

4

1.3 Outline of thesis

\section{CHAPTER 2 LITERATURE REVIEW}

2.0 Chapter overview

2.1 Triathlon sport 
$\begin{array}{ll}\text { 2.1.3 Long Course } & 6\end{array}$

2.1.4 Triathlete anthropometrics 9

2.2 Injuries in ironman triathlon

2.2.1 Type, Incidence, Prevalence 10

2.2.2 Bike positioning and its effect on injury 11

2.23 Orthotics and injuries in Triathletes 12

2.2.4 Predictors of Triathlon Injuries 13

2.2.5 Injuries in Australian Ironman Triathletes 15

2.2.6 Gender Difference in Triathlon Injuries 16

$\begin{array}{lll}2.3 & \text { Stretching } & 16\end{array}$

$\begin{array}{ll}\text { 2.3.1 Definitions of Stretching } & 17\end{array}$

2.3.2 Different Stretching Techniques 20

2.3.3 Static Stretching $\quad 22$

2.3.4 Contract Relax Stretching 28

2.3.5 Comparison of Different Stretching Methods 29

2.3.6 Electrical Activity of Muscles during Stretching 31 
3.1 Study design

3.2 Participant recruitment

3.3 Human ethics and race organisers approval

3.4 Questionnaire development

3.5 Questionnaire structure

3.6 Data analysis

4.0 Results introduction

4.1 Representative sample 
4.3 Respondent training characteristics

4.4 Stretching

4.5 Resources listed by respondents to learn stretches

4.6 Coaching

4.6.1 Triathlon coach

4.6.2 Swim coach

4.6.3 Cycle coach

4.6.4 Running coach

4.7 Training squads

4.7.2 Swim squad

4.7.3 Cycle squad

4.7.4 Running squad 
5.3.3 Coaching

5.3.4 Triathlon coach

5.3.5 Swimming Coach

5.3.6 Cycling coach 
5.5.5 Time to complete the race

5.5.6 Training hours and injury 


\section{LIST OF TABLES}

Table 2.2 Test results of hamstring muscle stretches on healthy subjects.

The changes in angle have been measured at the hip joint with the knee extended or of the knee with the hip flexed at 90 degrees.

Table 4.1 Age and gender of respondents and race participants

Table 4.2 Characteristics of respondents

Table 4.3 Best previous time to complete Ironman triathlon in 2005 or previous years

Table 4.4 Competitive sports respondents participated in prior to triathlon racing

Table 4.5 Gender differences in training loads of Ironman triathletes

Table 4.6 Regularity of stretching before training

Table 4.7 Regularity of stretching after training

Table 4.8 Time respondents held their stretches

Table 4.9 Number of times respondents performed stretches

Table 4.10 Body areas stretched by respondents

Table 4.11 Resources listed by respondents to learn stretches 
Table 4.13 Attributed causes of injury in various areas of the body

Table 4.14 Total injuries and time to complete race previously

Table 4.15 Strength training and stretch training relationships to injured body areas

Table 4.16 Days unable to train

Table 4.17 Days that athletes had to modify their training

Table 4.18 Orthotic wearers and injured parts of the body

Table 4.19 Use of orthotics and frequency of stretching after training

Table 4.20 Health professionals the respondents consulted for injured body areas

in order of frequency consulted

Table 4.21 Strategies respondents found best helped their injuries 
Table 5.1 Mean Age

Table 5.2 Characteristics of Race Respondents

Table 5.3 Males and Females Training Loads

Table 5.4 Strength and Stretch Training

Table 5.5 Competitive sport prior to triathlon

Table 5.6 Orthotic wearers and injured parts of the body

Table 5.7 Orthotics and Stretching After Training

Table 5.8. Time to complete the race

Table 5.9 Total injuries and time to complete race.

Table 5.10 Unable to train

Table 5.11 Modify to train

Table 5.12 Strength training and stretch training relationship to injured body areas

Table 5.13 Injured Body Areas

Table 5.14 Attributed Causes to injured areas of the body

Table 5.15 Professionals respondents sought advice to injured body areas

Table 5.16 Strategies respondents found best helped their injuries

Table 5.17 The athletes that stretched before training 
Table 5.18 The athletes that stretched after training

Table 5.19 Time respondents held their stretches

Table 5.20 The number of times respondents performed their stretches

Table 5.21 Areas Stretched by respondents

Table 5.22 Resources the respondents used to learn stretches

Table 6.1 Weekly Training Loads

Table 6.2 Strengthening and stretching loads

Table 6.3 Injured Body Areas 


\section{LIST OF FIGURES}

Figure 2.1 Chrissie Wellington world ironman triathlete on aerodynamic bars

Figure 2.2 Fuel Belt used by ironman triathletes in the run leg.

Figure 5.1 Mean of athletes total injuries with athletes stretching after training 


\begin{abstract}
The Ironman triathlon is an individual sport consisting of three disciplines - swimming, cycling and running. This endurance sport has grown in popularity with over 22 races annually worldwide and 24,000 participants. Despite this participation there are insufficient data concerning injuries in the Ironman triathlon and regarding athletes' stretching and training habits, especially in Australia. The aim of this retrospective cross-sectional study was to investigate the incidence of overuse injuries in this sport according to anatomical site, and their relationships to gender, age, training hours, stretching habits and other factors.

Questionnaires were provided in the race packs of 1250 participants of the Australian Ironman Triathlon in 2006. Two hundred and ninety-six questionnaires were returned giving a low response rate of $24 \%$ ( $74.3 \%$ male, $25.7 \%$ female). In this sample, $86.1 \%$ reported suffering an overuse injury related to competition or training in the last year. The most common site of injury was the knee (35.1\% of respondents), followed by the lower back $(34.1 \%)$ and the ankle/foot (30.7\%). There was no statistical relationship between incidence of injury and training load, gender or age, however triathletes with a triathlon coach had a lower injury rate. Participants reported stretching less before training $(41.2 \%)$ than after training (67.2\%). Among those participants who stretched, the most commonly stretched muscle groups were the hamstrings $(88.9 \%)$, calves $(88.5 \%)$ and quadriceps $(86.1 \%)$. The lower back (61.5\%), upper back (31.8\%) and shoulder (53.4\%) muscles were not stretched by as many participants. Lower back injuries had a significant association with cycling $(\mathrm{n}=$ $101, r=0.256, p=0.01)$. A strong positive trend was demonstrated between stretching after training and a reduction in total injuries $(\mathrm{p}=0.059)$. The health professional intervention most utilised by participants was physiotherapy. The overuse injuries in Ironman triathlons in other countries were reported to be most common in the knee, ankle/foot and lower back, which
\end{abstract}


was confirmed in this study of Australian Ironman triathletes. These areas injury need further investigation, to develop interventions to prevent or minimise injuries in this population.

There is a need to educate physiotherapists on the injury profile of these athletes, so they are better prepared to treat and design interventions to prevent these types of injuries. 